\title{
DOCÊNCIA NA EDUCAÇÃO SUPERIOR: COMPREENSÕES DAS RELAÇÕES DE (IN)DISSOCIABILIDADE COM A PESQUISA E A EXTENSÃO NA ATUAÇÃO PROFISSIONAL
}

\section{Teaching in Higher Education: Understanding Relationships of (In)dissociability with Research and Extension in Professional Performance}

\author{
Cátia Keske ${ }^{1}$ \\ Cátia Maria Nehring ${ }^{2}$ \\ Maria Cristina Pansera de Araújo ${ }^{3}$ \\ Sirlei Rigodanzo ${ }^{4}$ \\ Tamini Wyzykowski ${ }^{5}$
}

\begin{abstract}
Resumo: Nosso objetivo, nesta produção, é compreender alguns desafios da docência na Educação Superior, focando na indissociabilidade entre ensino, pesquisa e extensão, a partir do entendimento de que as instituições têm a responsabilidade de promover o ensino, a pesquisa e a extensão, porém, nem sempre o professor deste nível realiza essas três dimensões em sua atuação. A investigação foi realizada a partir de um questionário respondido por sessenta e nove professores que atuavam na Educação Superior, no ano de 2019. A pesquisa é de natureza qualitativa e os dados foram organizados pelo ciclo de operações da Análise Textual Discursiva (ATD). Os resultados construídos foram problematizados em duas categorias emergentes no corpus textual: a) saberes docentes e constituição profissional e b) práticas institucionais e formação acadêmica e profissional. A análise aponta que a docência é uma atividade complexa e fundamental para a formação humana e profissional. A indissociabilidade das atividades de
\end{abstract}

\footnotetext{
${ }^{1}$ Aluna do Programa de Pós-Graduação em Educação nas Ciências - Doutorado - na Universidade Regional do Noroeste do Estado do Rio Grande do Sul (Unijuí). Docente Educação Básica, Técnica e Tecnológica do Instituto Federal Farroupilha (IFFar). Orcid: http://orcid.org/0000-0002-3700-8634. E-mail: catia.keske@iffarroupilha.edu.br.

2 Doutorado em Educação pela Universidade Federal de Santa Catarina (UFSC). Professora Adjunto 3 da Universidade Regional do Noroeste do Estado do Rio Grande do Sul (Unijuí), Departamento de Ciências Exatas e Engenharias (DCEEng) e Programa de Pós-Graduação em Educação nas Ciências - Mestrado e Doutorado. Reitora da UNIJUÍ - Gestão 2020/2023.

3 Doutora em Genética e Biologia Molecular pela Universidade Federal do Rio Grande do Sul (UFRGS). Professora da Universidade Regional do Noroeste do Estado do Rio Grande do Sul (Unijuí), Departamento de Biologia e Química e Programa de Pós-Graduação em Educação nas Ciências - Mestrado e Doutorado. Orcid: https://orcid.org/0000- 0002-2380-6934. E-mail: pansera95@gmail.com.
}

${ }^{4}$ Aluna do Programa de Pós-Graduação em Educação nas Ciências - Doutorado - na Universidade Regional do Noroeste do Estado do Rio Grande do Sul (Unijuí). Docente Educação Básica, Técnica e Tecnológica do Instituto Federal Farroupilha (IFFar). ORCID: http://orcid.org/0000-0002-9544-8611. E-mail: sirlei.koslowski@iffarroupilha.edu.br.

5 Aluna do Programa de Pós-Graduação em Educação nas Ciências - Doutorado - na Universidade Regional do Noroeste do Estado do Rio Grande do Sul (Unijuí), Bolsista da Coordenação de Aperfeiçoamento de Pessoal de Nível Superior (CAPES). Orcid: https://orcid.org/0000-0001-9821-2463. E-mail: tamini.wyzykowski@gmail.com. 
ensino, pesquisa e extensão se constitui como meio e condição para o desenvolvimento de práticas educativas articuladas na contemporaneidade.

Palavras-chave: Constituição profissional docente. Instituições de Educação Superior. Práticas Institucionais.

\begin{abstract}
Our objective, in this production, is to understand some challenges of teaching in higher education, focusing on the inseparability between teaching, research and extension. It is fundamental to understand that institutions have the responsibility to promote teaching, research and extension, however the professor at this level does not always realize these three dimensions in his work. The investigation was conducted based on a questionnaire answered by sixty-nine teachers who worked in higher education in 2019. The research is of a qualitative nature and the data were organized by the operations cycle of Discursive Textual Analysis (DTA). The constructed results were problematized in two categories emerging in the textual corpus: a) teaching knowledge and professional constitution and b) institutional practices and academic and professional training. The analysis points out the teaching is a complex and fundamental activity for human and professional development. The inseparability of teaching, research and extension activities constitutes itself as a means and condition for the accomplishment of educational practices articulated in contemporaneity.
\end{abstract}

Keywords: Teaching professional constitution. Higher Education Institutions. Institutional Practices.

\title{
1 Introdução
}

Somos um país vasto em termos de fronteiras geográficas e diverso quanto à densidade demográfica, às atividades econômicas e às configurações socioculturais. Tantas diferenças configuram especificidades locais e regionais perpassadas, porém, por necessidades comuns, dentre as quais: a formação proporcionada pela Educação Superior e a ênfase na qualidade desse nível de ensino. Outrossim, as diferentes realidades do território brasileiro delineiam um duplo desafio às Instituições de Ensino Superior (IES): pensar e projetar-se como espaço-tempo de ensino, pesquisa e extensão e desenvolver ações acadêmico-científicas que contemplem a constituição humana e profissional dos sujeitos, predispondo-os a problematizar e se movimentar, (re)conhecendo o contexto social local e regional em que atuam/atuarão.

Compreender o contexto atual da Educação Superior no Brasil exige, assim, percebêla, de forma singular, como espaço e tempo de formação humana e profissional. Pensar o tema é importante, especialmente, quanto às transformações no campo da legislação educacional, da profissionalização docente e das concepções sobre a formação dos acadêmicos. Ao encontro dessa intenção, emerge a urgência de (re)pensar a relação entre os princípios filosóficos, éticos e administrativos e as práticas das IES - nas dimensões ensino, pesquisa e extensão. É importante problematizá-las como espaços múltiplos e complexos de: diferentes culturas, investigação científica e de produção e socialização de conhecimentos; ensino das profissões em perspectiva de formação humanizadora e acadêmico-profissional e de compromisso social; educação ética, cidadã e de transformação social.

Essa multiplicidade de fins e objetivos suscita reflexão sobre a docência no Ensino Superior. O ato de refletir é, nesse contexto, fundamental aos processos de ensinar e aprender nas diferentes formas de oferta de cursos de graduação - tecnólogos, bacharelados ou licenciaturas - e de pós-graduação - lato ou stricto sensu. 
Vivemos em meio à multiculturalidade, pari passu aos ditames das tecnologias e da globalização, contexto que constitui dilemas pelos quais docentes se encontram na Educação Superior: questões coletivas e individuais de formação profissional na atualidade. Ser professor(a) na Educação Superior implica, assim, buscar (re)conhecer as demandas e necessidades de aprendizagem no contexto da atualidade, demarcada por características da pósmodernidade bem como da modernidade. Trata-se de ensinar de forma a subsidiar processos cognitivos críticos e autônomos para a compreensão e enfrentamento dos desafios (im)postos pelo século XXI às diferentes profissões. Tarefa complexa?

Para Cunha (2018, p. 7), "o tema da profissão docente tem sido inesgotável. Essa condição se justifica porque a instituição escolarizada é socialmente referenciada, ou seja, seu papel social e cultural se movimenta em função dos valores e contextos, que se instituem na sociedade". A autora também comenta que a "expectativa em relação à docência se movimenta na dependência da expectativa sobre os objetivos das instituições formadoras", visto que, na atualidade, a finalidade da educação perpassa os vários campos do saber, nos quais o docente "deve ter o domínio completo de um campo de saber constituindo a base da formação e do desempenho docente, e a sua professoralidade se sustenta na segurança do domínio do conteúdo, na palavra abalizada reconhecida como a verdade" (CUNHA, 2018, p. 7).

A atuação do professor na Educação Superior é, por vezes, pautada no papel social das IES. Desse modo, se configura como uma das atribuições dos docentes o desenvolvimento do ensino, da pesquisa e da extensão, potencializando a produção de conhecimentos capazes de transformar o contexto social em que sua instituição está inserida (ALMEIDA, 2012).

Alguns autores como Nóvoa (1992) e Almeida (2012) direcionam seus estudos no percurso de identificar elementos para auxiliar na definição das dimensões profissional, pessoal e organizacional, que estão implicadas na prática profissional dos sujeitos professores. Vale observar que essas dimensões se entrecruzam, se sobrepõem, se combinam das mais variadas formas, levando em consideração as características e trajetórias pessoais dos docentes e a multiplicidade de IES. Em virtude disso, emerge uma preocupação latente em relação a de que modo a docência e o trabalho do professor em sala de aula impacta na formação dos alunos (ALMEIDA, 2012).

Nesse sentido, Cunha (2018, p. 8) enfatiza que "não basta saber fazer, é preciso compreender teoricamente por que se faz e as consequências dessas ações como professores". A autora aponta a necessidade de desenvolver uma capacidade reflexiva sobre e para a transformação das "práticas de ensinar e aprender, à ampliação do diálogo epistemológico interdisciplinar, ao trânsito entre ciência, cultura e sociedade e às práticas mais coletivas e solidárias de produção" Ainda, segundo ela, "essas se constituem em habilidades emergentes no contexto da universidade contemporânea" (CUNHA. 2018, p. 8).

Pautar-se na perspectiva do desenvolvimento de capacidades e habilidades de pensamento dos alunos é um dos objetivos das IES. Enfatizar o desenvolvimento da razão crítica, por meios didáticos e pedagógicos, em uma sólida formação cultural e científica, o domínio de competências cognitivas que levem os estudantes a "aprender a pensar", contribuir para a construção pessoal dos alunos e fortalecer a cidadania participativa permite, conforme Libâneo (2011), elaborar, ser um caminho. Para tanto, a formação de professores para atuar na Educação Superior é uma questão que necessita ser problematizada. Pensar princípios e processos formativos requer que os docentes compreendam o cenário de sua atuação profissional de maneira crítica. Esse desafio pode ser mediado no âmbito da formação 
continuada, em serviço, pela reflexão da sua práxis $^{6}$ de ensino, pesquisa e extensão. Nessa direção, Alarcão (2011, p. 33-34) assim se manifesta:

eu diria que, primeiro que tudo, os professores têm que repensar o seu papel. Se é certo que continuam a ser fontes de informação, têm de se consciencializar que são apenas uma fonte de informação, entre muitas outras. Deve, no entanto, salientar-se que o seu valor informativo tem níveis diferentes conforme o acesso que os seus alunos puderem ter a outras fontes de informação. É fundamental que os professores percebam esta diversidade. Haverá alunos que não vão precisar muito da informação substantiva dos professores, embora precisem da informação processual no sentido de a digerirem e criticarem. Porém, outros alunos necessitarão que o professor os informe sobre a substância e sobre o processo.

A atuação docente, antes e, algumas vezes ainda, somente atribuída à socialização do conhecimento a partir do ensino, ganhou novos contornos na contemporaneidade. Na Educação Superior, os elementos norteadores da efetivação do papel social da docência, além e junto ao ensino, também acabam por residir na pesquisa, na extensão universitária e, mesmo que em contexto inicial, na inovação pedagógica e tecnológica.

Docentes das IES têm o papel de formar profissionais atentando para a produção de conhecimento científico na interlocução entre a formação humana, técnica e tecnológica. Os estudantes buscam desenvolvimento e qualificação profissional. Na correlação destas intenções, estão os dramas dos desafios às IES e aos profissionais docentes que nelas atuam, tecidos em meio a, e por um mundo highly technological, pela necessidade do trabalho e diante de transformações sociais, históricas e culturais. Nessa trama, justifica-se pensar estratégias, práticas institucionais e questões didático-pedagógicas que vão ao encontro de uma sólida formação geral por meio de ensino, pesquisa e extensão, estreitamente articulados teórica e metodologicamente.

De acordo com Cunha (2018), a Educação Superior tem sido influenciada por fenômenos contemporâneos que podem abalar o imaginário dos docentes sobre a profissão, motivo de abarcar novos desafios, além de pensar o ensino e a pesquisa e a curricularização da extensão universitária. Assim, "compreender essa pluralidade de exigências pressupõe assumir a docência como ação complexa que requer saberes disciplinares, culturais, afetivos, éticos, metodológicos, psicológicos, sociológicos e políticos" (CUNHA, 2018, p. 10).

Em suma, pensar sobre as demandas direcionadas à Educação Superior e aos professores que a constituem, considerando-a especificamente como campo de atuação profissional, conduz a reconhecer que elas são bastantes e ingentes. Ademais, as IES se instituem a partir da sociedade e, por conseguinte, necessitam se transformar, a fim de atender a sociedade, contribuindo para o seu pleno desenvolvimento.

Ao encontro dessas premissas e considerando o atual contexto brasileiro, no que tange à ampliação quantitativa da oferta e da procura pela Educação Superior, importa perceber quais são as demandas dos sujeitos que a buscam e, nesta pesquisa em especial, as concepções que

\footnotetext{
6 Para Schön (1992, p. 91), "todo o processo tem envolvido uma reflexão coletiva sobre a prática do sistema escolar e tem tido grande impacto nos professores, [...] o que significa, então, tentar formar um professor para que ele se torne mais capaz de refletir na e sobre a sua prática? ". Em síntese, Schön (1992) aponta três dimensões de reflexão sobre a prática no desenvolvimento de um practicum reflexivo (a compreensão das matérias pelo aluno, a interação interpessoal entre o professor e o aluno e a dimensão burocrática da prática) incitando, por fim, à reflexão sobre a possibilidade de valorizarmos e fomentarmos a constituição dos practicums nas escolas.
} 
orientam e subsidiam as ações de quem a constitui. Nesse sentido, por meio de interações estabelecidas com professores que atuam na Educação Superior, através de um questionário, o objetivo central do presente trabalho é identificar entendimentos acerca da indissociabilidade entre ensino, pesquisa e extensão nas práticas profissionais de professores da Educação Superior, bem como desafios que no exercício da docência se apresentam para tal.

Temos como pressuposto inicial a compreensão de que a sociedade está envolvida em constantes transformações e que a Educação Superior não fugiu a essa regra. Tempos múltiplos, apressados, e movimentos que geraram mudanças de papéis nos sujeitos envolvidos (docentes e discentes) transformam os modos de ensinar e de aprender, diferenciam as concepções de conhecimento e de informação e comprometem a aprendizagem profissional. Para além das relações entre as disciplinas, mas sem deixar de considerá-las, a questão central que move a articulação dos projetos institucionais é a do conhecimento. Nessa direção, dialogar com a sociedade contemporânea implica pensar a indissociabilidade entre ensino, pesquisa e extensão e as demandas sociais que as envolvem com a Educação Superior.

À vista disso, temos a premissa de que este estudo poderá fomentar reflexões sobre alternativas que promovam transformações qualitativas nos processos formativos da Educação Superior e, consequentemente, no percurso de desenvolvimento humano e profissional dos sujeitos que constituem os espaços acadêmicos.

\section{$2 \mathrm{O}$ contexto investigativo e os procedimentos metodológicos}

A metodologia desta investigação é uma abordagem qualitativa de pesquisa em Educação (LÜDKE; ANDRÉ, 1986). Para a produção deste trabalho, utilizamos como fonte de dados as respostas a um questionário formulado no contexto da disciplina Ensino Superior: Perspectivas das Ações do Professor, vinculada aos cursos de mestrado e doutorado do Programa de Pós-Graduação em Educação nas Ciências da Unijuí, no ano de 2019. Tais respostas serviram como exercício de problematização das atividades acadêmicas propostas aos discentes matriculados no Programa.

No presente artigo, analisamos os dados produzidos por meio do questionário semiestruturado, cujo desenvolvimento seguiu a seguinte dinâmica: cada mestrando ou doutorando matriculado na disciplina ficou responsável por enviar o questionário para três professores da Educação Superior, conforme suas relações pessoais, acadêmicas e/ou profissionais, independentemente de curso, área ou etapa de atuação, contanto que fosse na graduação ou pós-graduação. Composto por 23 perguntas, o instrumento elaborado pelas professoras responsáveis pela disciplina foi respondido por 69 professores de instituições federais, privadas ou comunitárias, no primeiro semestre de 2019. As respostas registradas constituíram um banco de dados, tabulado em planilha Excel. A partir disso, a proposta da disciplina contemplou a escrita de artigo com um recorte temático voltado ao tripé ensinopesquisa-extensão. Todos os alunos matriculados tiveram acesso à planilha de dados, podendo utilizá-la para desenvolver uma pesquisa e produzir o trabalho proposto na disciplina, em duplas ou trios. Neste sentido, considerando nosso interesse pela compreensão de relações estabelecidas (ou não) com a pesquisa e a extensão na prática docente na Educação Superior, sistematizamos esta escrita a partir da análise das respostas atribuídas pelos participantes especificamente à questão: "Você considera as atividades de pesquisa e de extensão em sua atividade de ensino? Como?".

Salientamos que os sujeitos da pesquisa autorizaram a divulgação das informações registradas no questionário e, observando a Resolução 510/2016 do Conselho Nacional de 
Saúde (CNS), mantemos a identidade de cada um deles preservada (BRASIL, 2016). Por essa razão, as manifestações dos participantes são apresentadas com grifos em itálico e designadas pela letra $\mathrm{P}$, de professor, seguida de um número, iniciando em P1, P2 e assim sucessivamente até P69, a fim de manter o anonimato dos sujeitos envolvidos e a autoria dos excertos transcritos.

A Figura 1 apresenta a relação dos sujeitos da pesquisa quanto à segmentação por instituição de atuação, sexo e idade, sendo a maior parte mulheres, na faixa etária de 31 a 35 anos e docentes que atuam na rede pública de ensino superior, Institutos Federais e Universidades.

Figura 1 - Gráficos das 69 respostas registradas no questionário com base em instituição, sexo e idade.

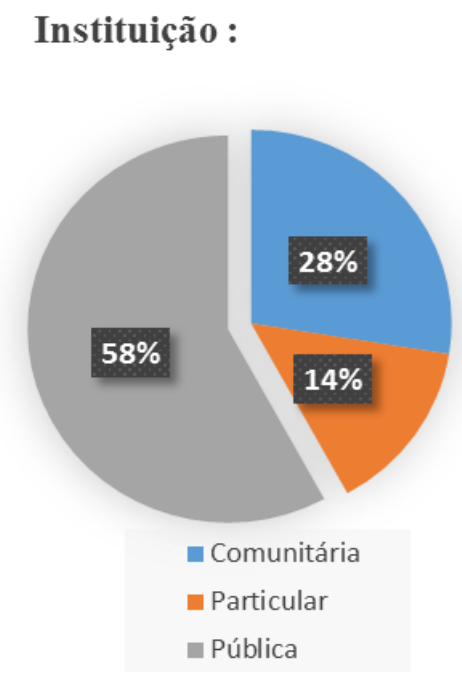

Sexo:

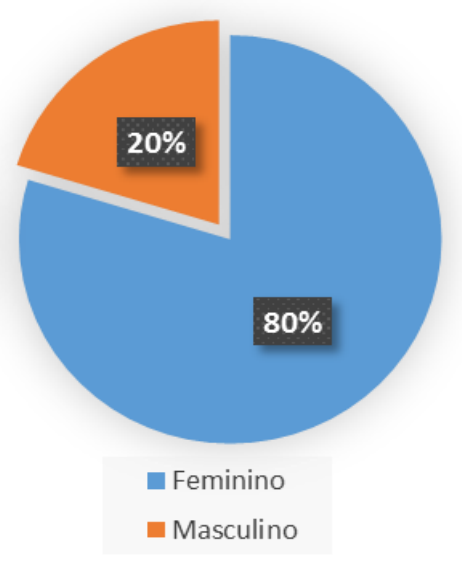

Fonte: Elaborado pelas autoras

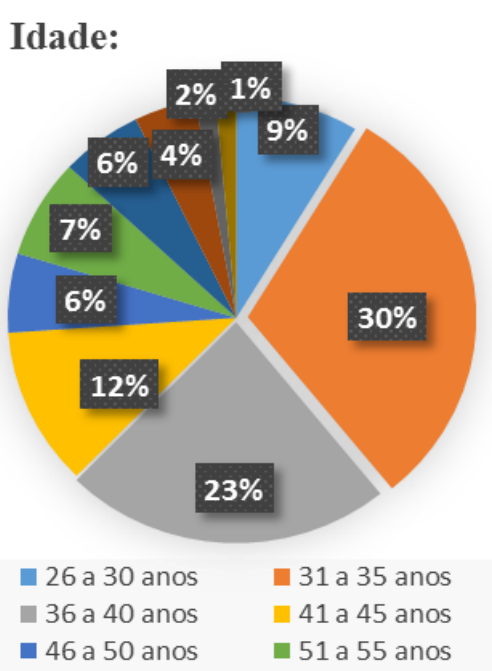

A organização dos dados considera os pressupostos teóricos da Análise Textual Discursiva (ATD), conforme propõem Moraes e Galiazzi (2006). Segundo esses autores, a ATD possibilita a análise de conteúdos e discursos em pesquisas qualitativas e caracteriza-se pela realização das etapas de unitarização, categorização e captação de novo emergente sob o corpus textual de análise.

A análise textual discursiva é descrita como um processo que se inicia com uma unitarização em que os textos são separados em unidades de significado. Estas unidades por si mesmas podem gerar outros conjuntos de unidades oriundas da interlocução empírica, da interlocução teórica e das interpretações feitas pelo pesquisador. Neste movimento de interpretação do significado atribuído pelo autor exercita-se a apropriação das palavras de outras vozes para compreender melhor o texto. Depois da realização desta unitarização, que precisa ser feita com intensidade e profundidade, passa-se a fazer a articulação de significados semelhantes em um processo denominado de categorização. Neste processo reúnem-se as unidades de significado semelhantes, podendo gerar vários níveis de categorias de análise. A análise textual discursiva tem no exercício da escrita seu fundamento enquanto ferramenta mediadora na produção de significados e por isso, em processos recursivos, a análise se desloca do empírico para a abstração teórica, que só pode ser alcançada se o pesquisador fizer um movimento intenso de interpretação e produção de argumentos (MORAES; GALIAZZI, 2006, p. 118). 
No deslocamento do empírico para a abstração teórica proposta pelos autores, buscamos interpretar e discutir os resultados, em diálogos com aqueles que discorrem sobre a Educação Superior e constituem o aporte para produção de argumentos sistematizados neste estudo, com destaque para Almeida (2012), Cunha (2018) e Franco (2013).

\section{Compreensões desveladas pela ATD: a indissociabilidade de ensino, pesquisa e extensão na Educação Superior}

Como uma "tempestade de luz", analogia estabelecida por Moraes (2003, p. 192), o processo analítico da ATD constituiu-se na emergência, no meio caótico e desordenado, de "flashes fugazes de raios de luz" que iluminaram desafios à Docência na Educação Superior na contemporaneidade, quanto à indissociabilidade entre ensino, pesquisa e extensão, fenômenos investigados neste estudo.

Ao unitarizar, desvelamos entendimentos quanto às atividades de pesquisa e extensão no ensino. A maior parte das respostas do questionário afirma ser possível e necessário relacioná-las (47 dos 69 professores assim indicaram); um grupo relativiza a prática de indissociabilidade, reconhecendo como importante, porém inviável em algumas situações (17 dos 69 professores problematizaram a questão nessa perspectiva); e 5 professores não responderam à pergunta do questionário. Na Figura 2, apresentamos as referidas informações sistematizadas a partir do processo inicial de ATD:

Figura 2 - Gráfico da Unitarização das 69 respostas registradas no questionário

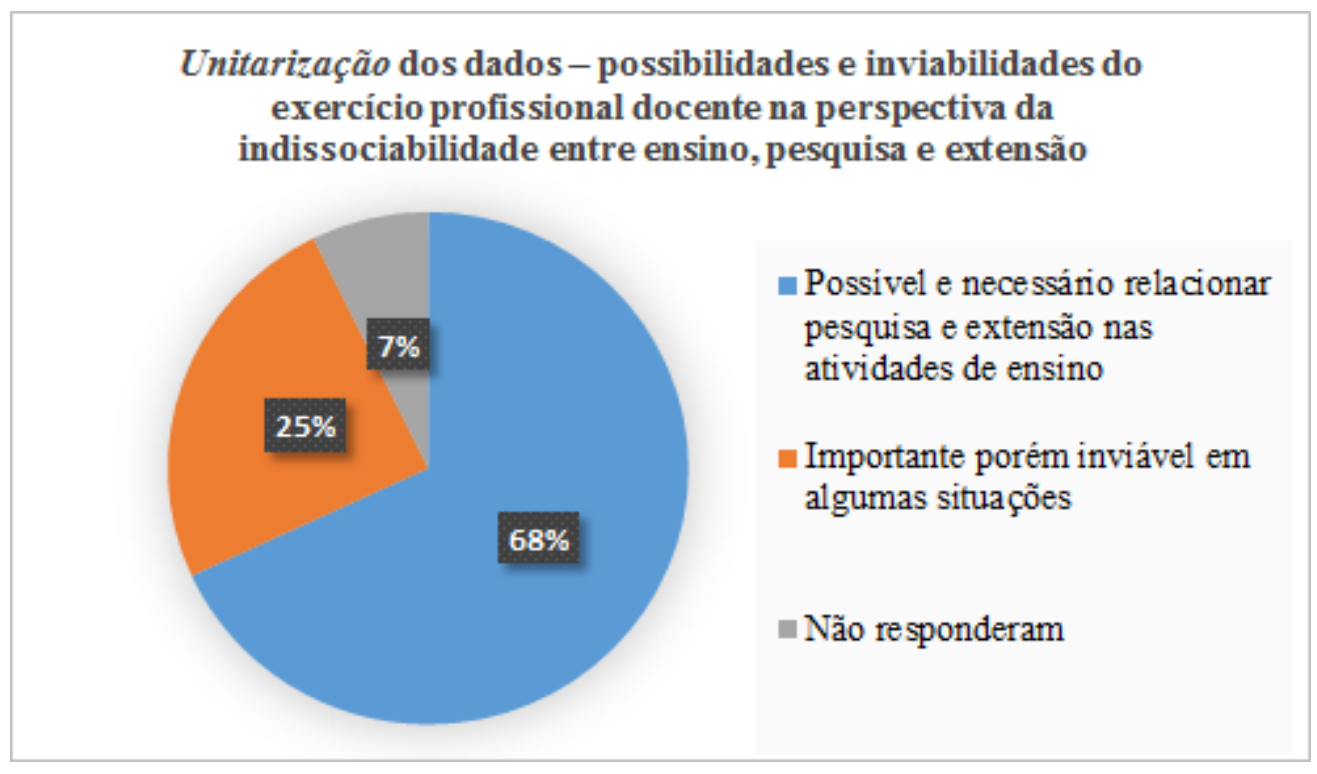

Fonte: Elaborado pelas autoras (2020).

Buscando identificar semanticamente os fragmentos do corpus textual, desconstruímos os entendimentos dos sujeitos da pesquisa. Na unitarização, reconhecemos a acepção direta e indireta da concordância à pergunta "Você considera as atividades de pesquisa e de extensão em suas atividades de ensino? ". No quadro 1, apresentamos o contexto de reconhecimento dos indicadores textuais que foram depreendidos nesse processo. 


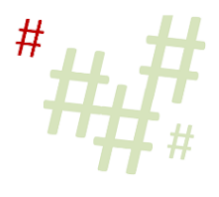

Quadro 1 - Indicadores textuais para expressar os entendimentos "possível e necessário relacionar pesquisa e extensão nas atividades de ensino" e "importante, porém inviável em algumas situações"

\begin{tabular}{|c|c|c|c|c|}
\hline Entendimentos & $\begin{array}{l}\text { Palavras e } \\
\text { expressões }\end{array}$ & $\begin{array}{l}\text { Palavras } \\
\text { referência das } \\
\text { derivações }\end{array}$ & Orações ou frases & $\begin{array}{c}\text { Períodos } \\
\text { (síntese nossa) }\end{array}$ \\
\hline $\begin{array}{l}\text { Possível e } \\
\text { necessário } \\
\text { relacionar } \\
\text { pesquisa e } \\
\text { extensão, nas } \\
\text { atividades de } \\
\text { ensino }\end{array}$ & $\begin{array}{c}\text { “Sim" } \\
\text { “Com certeza" } \\
\text { "Sempre" }\end{array}$ & $\begin{array}{l}\text { "Fundamental" } \\
\text { "Importante" } \\
\text { "Indissociável" }\end{array}$ & $\begin{array}{l}\text { "Defendo a pesquisa e a } \\
\text { extensão como norteadoras" } \\
\text { "Pesquisa e extensão possuem } \\
\text { relação com tudo que ensino } \\
\text { nos componentes curriculares" } \\
\text { "Pesquisa e extensão se } \\
\text { tornam evidentes" }\end{array}$ & \\
\hline $\begin{array}{l}\text { Importante, } \\
\text { porém inviável } \\
\text { em algumas } \\
\text { situações }\end{array}$ & $\begin{array}{l}\text { "Sempre que } \\
\text { possível" } \\
\text { "Não é sempre" } \\
\text { "De modo } \\
\text { muito } \\
\text { simplório" }\end{array}$ & "Parcial" & $\begin{array}{l}\text { "Importante, mas muito difícil } \\
\text { na minha instituição" } \\
\text { "Na maioria das vezes pela } \\
\text { carga horária, e cobranças, não } \\
\text { se pode trabalhar, } \\
\text { adequadamente a relação" }\end{array}$ & $\begin{array}{l}\text { "Relaciona-se } \\
\text { pesquisa sim, } \\
\text { não se } \\
\text { considera ou se } \\
\text { desenvolve } \\
\text { extensão". }\end{array}$ \\
\hline
\end{tabular}

Fonte: Elaborado pelas autoras (2020).

As palavras, expressões, frases, orações e períodos (Quadro 1), manifestados pelo conjunto de participantes da pesquisa, corroboram a relação entre ensino, pesquisa e extensão, sendo que alguns textos do corpus são descrições simples, outras descrições analíticas, embasadas teoricamente, ou ainda de mera concordância. Essas últimas não foram objeto da ATD, pela característica de simples concordância e, em uma análise rigorosa, no campo do senso comum, a exemplo das afirmações de P2 e P56, respectivamente: "sim, na maioria das vezes procuro abordar temas trabalhados em aula com esses três eixos (ensino, pesquisa e extensão)" (P2) e "na minha opinião, atuar em pesquisa e extensão é o que faz o professor se manter sempre atual no ensino" (P56).

Vale, sobretudo, salientar que, conforme autores como Sampaio e Freitas (2010), o ensino, a pesquisa e a extensão são três eixos estruturantes, que possuem identidades, caracterizam a Educação Superior e, por essas razões, precisam ser compreendidos como indissociáveis para que viabilizem às IES cumprir seu papel principal: formar profissionais com conhecimentos específicos, críticos em relação à historicidade e relevância social de sua profissão, capazes de agir com ética, comprometimento e cidadania nos diferentes espaços de atuação profissional.

Ainda, na direção de contribuir para o desenvolvimento social e econômico da comunidade, "produzindo e socializando conhecimentos que deem direito ao acesso à dignidade de vida de todas as pessoas" (SAMPAIO; FREITAS, 2010, p. 29), a indissociabilidade é de primordial importância: por meio do ensino, o contexto acadêmico oportuniza aos graduandos/futuros profissionais a significação de conhecimentos de sua área de formação. $\mathrm{O}$ desenvolvimento da pesquisa, vinculada a editais da instituição, com ou sem financiamento de órgãos externos de fomento e incluindo a participação de bolsistas de Iniciação Científica, de Mestrado e Doutorado prima pela produção de novos conhecimentos, que também são ensinados a fim de melhor formar os acadêmicos. E, também, ao identificar novos problemas 
da comunidade, tendo neles fatores para impulsionar novas discussões no contexto acadêmico, por meio da extensão, é possível socializar e desenvolver conhecimentos pesquisados/construídos junto a outros segmentos da sociedade.

Sem desconhecer a contribuição de entendimentos como os de P3 e P56, em especial, porque cumprem com a função de problematização, ao focar nas demais, a partir do processo de unitarização, aproximamo-las por meio da identificação semântica dos entendimentos recorrentes quanto a ser "possível e necessário relacionar pesquisa e extensão nas atividades de ensino" e ao fato de que é "importante, porém inviável em algumas situações".

No exercício de categorização, duas categorias emergiram ao encontro do objetivo do estudo - identificar entendimentos acerca da indissociabilidade entre ensino, pesquisa e extensão nas práticas profissionais de professores da Educação Superior, bem como desafios que no exercício da docência se apresentam para tal. Suscitada em ambas as recorrências, a relação indissociável entre ensino, pesquisa e extensão é expressa tanto na descrição de práticas profissionais docentes que se sustentam por saberes e conhecimentos teórico-metodológicos, quanto nos indicativos de práticas institucionais favoráveis e desfavoráveis a ela. Nesse contexto, problematizamos duas categorias emergentes em nossa análise: a) saberes docentes e constituição profissional; e b) práticas institucionais e formação acadêmica e profissional.

Para além de meramente concordar com a necessidade de, na Educação Superior, não somente desenvolver atividades de ensino, mas também de pesquisa e extensão de forma articulada, voltamo-nos aos participantes da pesquisa que apresentaram suas compreensões de forma ampliada e/ou contextualizaram-nas. Ao destacar e/ou descrever "como" relacionam pesquisa e extensão em suas práticas profissionais, discorreram ao defender tal relação, permitindo-nos reconhecer indícios de saberes e conhecimentos teórico-metodológicos constitutivos da docência na Educação Superior.

São compreensões que contêm em si a ideia de professor pesquisador, desenvolvimento profissional, como destacado por P3, ao evidenciar sua constituição como docente, e a busca de respostas para questões geradas nos contextos do ensino e da extensão, por meio da pesquisa:

Com certeza. Em minha atuação como professora não consigo conceber estas atividades de forma isolada. De forma orgânica e intimamente articuladas, ações de pesquisa, de extensão e de ensino me constituem. Ações de ensino e de extensão geram questões/problemas, os quais busco, por meio de ações de pesquisa, a produção de possíveis respostas, que possibilitam desenvolver-me profissionalmente (P3).

Ao encontro da "articulação íntima e orgânica entre ensino, pesquisa e extensão" defendida por P3, P5 descreve ações que demonstram a complementaridade entre as três dimensões:

\footnotetext{
Sempre procuro fazer isso. Como: complementando o ensino com os referenciais teóricos que me aproximo para o desenvolvimento de minhas pesquisas; utilizando recortes de situações, de contextos reais da educação ou dos processos de ensino que emergem nas atividades de extensão e pesquisas; utilizando resultados das minhas pesquisas para colocar em discussão no ensino (P5).
}

O professor P6 também evidencia a noção de professor pesquisador ao compartilhar o processo de produção e socialização de conhecimento: [...] atividades de pesquisa e extensão 
são consideradas a partir de leitura, escrita e prática que visam contribuir para com as dificuldades encontradas na sociedade. Temos grupo de pesquisa, publicamos escritas que desenvolvemos" e, também: "levamos conhecimento à comunidade" (P6).

Assim como esses entendimentos são reveladores de uma compreensão da pesquisa como processo constitutivo da docência na Educação Superior, também são de diferentes saberes docentes que, como profissional, o professor mobiliza ao ensinar, ao fazer pesquisa e ao fazer extensão. Reconhecer-se como sujeito que se constitui profissionalmente em um processo formativo implica identificar e ressignificar os sentidos dados, e que sustentam suas diferentes práticas.

Problematizando o quanto o ensino tarda a refletir sobre si mesmo e não tem definido os saberes envolvidos no exercício do seu ofício, apesar de vir sendo desenvolvido desde a Antiguidade e sem interrupção, Gauthier et al. (2013) sugerem a condição de ignorância em relação a si próprio. Na defesa da necessidade de uma teoria geral da Pedagogia, identificam dois obstáculos que, historicamente, se interpõem a ela, quais sejam: "ofício sem saberes" e os "saberes sem ofício"; e propõem um "ofício feito de saberes". Como caminho para evitar os dois erros, defendem uma concepção que considere a mobilização de vários saberes, constitutivos de um "[...] reservatório no qual o professor pode se abastecer para responder a exigências específicas de sua situação concreta de ensino" (GAUTHIER et al., 2013, p. 28), que pode contribuir ao desafio da profissionalização docente na Educação Superior.

Parece-nos, como os dados indicam, que, na Educação Superior, os saberes docentes se constituem na (super)valorização das atividades de ensino e, em segundo plano, de pesquisa. Na categoria a) saberes docentes e constituição profissional, localizamos um grupo significativo de falas que expressam, de forma direta ou indireta, a articulação de pesquisa e ensino, na sobreposição da relação extensão e ensino (Quadro 1), ao indicar, por meio de síntese nossa, "Relaciona-se pesquisa sim, não se considera ou se desenvolve extensão". De forma indireta, são falas como as de P57:

[...] busco atualizar os alunos por meio dos dados de pesquisa, desenvolvidos por mim e/ou pela comunidade científica em geral. Além disso, busco utilizar as áreas de pesquisa para mostrar aos alunos sobre as teorias, processos que discutimos em sala de aula" e de P68: "no momento, atuo principalmente com atividades de pesquisa e elas se formam elementos que são retomados em determinadas disciplinas.

Diretamente, P47 compartilha que: "contudo, a atividade de extensão é um aspecto que preciso reorganizar. Penso que ainda são restritos os momentos em que contemplo a extensão na minha prática de ensino, no Ensino Superior".

Se desvelamos saberes docentes constitutivos da formação profissional, na segunda categoria emergente no entrelaçamento dos entendimentos "possível e necessário relacionar pesquisa e extensão nas atividades de ensino" e "importante, porém inviável em algumas situações" - b) práticas institucionais e formação acadêmica e profissional -, relacionamos as ideias de coletividade e formação continuada de professores. A expressão a seguir contribui para introduzirmos a primeira delas: "articulações com as atividades de ensino devem ser pensadas sempre em um coletivo, pois as disciplinas que envolvem uma grade curricular, devem ser pensadas articuladas a estas dimensões atendendo às Diretrizes, Missão e Valores institucionais" (P4). Na esteira desse sujeito de pesquisa, problematizamos o quanto as IES atendem diretrizes e como elaboram sua Missão e Valores institucionais.

Na Educação Superior, os profissionais que nela atuam são sujeitos dela constitutivos, com condições específicas e singulares para problematizar a atualidade, tanto de políticas 
públicas quanto de propostas pedagógicas. A consolidação e/ou alteração de suas práticas de ensino, pesquisa e extensão podem tencionar uma adequada política educacional (GOMES; MACHADO-TAYLOR; SARAIVA, 2018). Para tanto, reconhecer e analisar o contexto histórico e legal deste nível da educação pode permitir clareza e objetividade sobre a continuidade e manutenção ou não de um sistema, da defesa ou não desta ou daquela Missão e Valores. Dada a possibilidade de se redefinir caminhos, mudanças, entretanto, isso acontece por meio de proposições não somente individuais, mas, especialmente, coletivas. A coletividade, no contexto educativo, tem caráter também propositivo e reivindicador de políticas e (re)definições teórico-filosóficas ao encontro da expansão do acesso e permanência em cursos superiores.

Para tanto, são necessárias práticas, intencionalidades institucionais favoráveis a ela e, ao pensar o âmbito das práticas institucionais, não podemos deixar de considerar que na Educação Superior também há dificuldades que acometem (muitas vezes fazem adoecer) o docente, como bem ilustra P54, ao indicar não considerar as dimensões da pesquisa e da extensão em suas atividades de ensino:

\begin{abstract}
Pois é: este é o meu espaço vazio. Não considero. Havendo uma maior preocupação com as atividades de ensino, para cumprir as determinações do semestre letivo. Acho que este é um grande problema que pode ser presente em todas as universidades e para todos os professores do ensino superior. $\mathrm{O}$ atendimento das atividades normais de ensino, fazendo com que pesquisa e extensão sejam secundarizadas, mesmo que tenhamos dedicação exclusiva. As atividades de ensino, nos tomam por inteiro, porque há a necessidade do vencimento de um semestre e dos prazos curriculares e letivos. Entendo que este fator dificulta as atividades de pesquisa e de extensão. Assim, as atividades curriculares e letivas se sobrepõem à pesquisa e à extensão, o que não é salutar para, inclusive, as atividades de ensino. Sempre é colocada a relação de ensino pesquisa e extensão, mas na maioria das vezes pela carga horária, e cobranças, não se pode trabalhar adequadamente a relação (P54).
\end{abstract}

Considerando o que Franco (2013) propõe ao enfatizar a Didática e a Pedagogia em mútua e contínua articulação em perspectiva de análise, compreensão e transformação das práticas pedagógicas na Educação Superior, destacamos uma premissa essencial ao contexto institucional que se queira favorável, não somente à coletividade docente, mas à qualidade sociocultural, científica e tecnológica da formação que oferta: uma Proposta Pedagógica coletiva, integrando as lógicas de alunos, professores e instituições, tendo na Didática (como área da Pedagogia como Ciência) uma teoria da formação, e não teoria do ensino.

Sobretudo, é imprescindível pensarmos a problematização feita por P54 como "preocupação" para com a formação acadêmica e profissional do estudante da Educação Superior, também evidenciada por diferentes sujeitos da pesquisa. Seguindo a linha de pensamento, P14, por exemplo, destaca: "Considero as atividades como fundamentais e percebo no cotidiano o diferencial dos alunos que estão envolvidos em pesquisa e extensão dos demais pela capacidade de aprofundamento nas discussões em sala de aula e nos ambientes de prática". Ao encontro disso, P33 descreve analiticamente o seu "como", relacionando atividades de pesquisa e extensão ao ensinar, indicando que estas "se tornam evidentes nas ações que envolvem grupos de acadêmicos comprometidos em refletir e expandir conhecimentos apreendidos nas atividades de ensino". Em sua prática profissional na Educação Superior (como formadora em curso de licenciatura), esse processo compreende: 
[...] estudos de referenciais teóricos, que contribuem para planejamento de sequências didáticas, a serem implementadas nas escolas da rede regular de ensino, especialmente na educação básica. A partir do momento em que as sequências didáticas são implementadas, os dados coletados através das atividades dirigidas aos estudantes podem ser analisados. Os dados analisados são confrontados com o referencial bibliográfico inicialmente utilizado para o planejamento. Essas ações possibilitam a formação de profissionais autônomos, reflexivos, críticos e éticos na busca de indícios de aprendizagem significativa (P33).

$\mathrm{Na}$ direção da postura identificada por P14 e P33, está a de P35, que descreve a indissociabilidade em um "como fazer" que contribui ao processo de aprendizagem do sujeito que está em formação profissional e acadêmica: "de modo geral, penso que na pesquisa reside a descoberta; no ensino, a socialização/problematização das descobertas e, na extensão, a sua aplicabilidade com vistas a destacar as contribuições da pesquisa para a comunidade" (P35). Tais entendimentos remetem à proposição de Franco (2013) sobre o contexto de uma sala de aula da Educação Superior. Para a autora, é essencial pensar e propô-la por meio de processos investigativos, através dos quais alunos e professores se organizem num coletivo investigador, que pode facilitar o envolvimento dos sujeitos com os processos coletivos de produção, sistematização e socialização dos conhecimentos (FRANCO, 2013).

Por fim, há que se destacar que a constatação do reconhecimento de relações possíveis com as dimensões da pesquisa e da extensão, ao ensinar, indica, direta ou indiretamente, conhecimento acerca da relação ensino-pesquisa-extensão como tripé da Universidade. Se tomarmos tal relação, bem como o desenvolvimento de cada uma das dimensões que a compõem, somente como exigência legal, inferiríamos que as respostas que dão corpo a esta compreensão são de professores que atuam em Universidades, dado que as demais IES estão desobrigadas a cumpri-la. Temos o entendimento ampliado da caracterização de Universidade entre alguns sujeitos da pesquisa, como P12, que destaca entender que "[...] o princípio da indissociabilidade entre Ensino, Pesquisa e Extensão não pode ser trabalhado de forma individualizada[...]", citando a acepção de Boaventura de Sousa Santos (2005) quanto ao sentido mais intrínseco da Universidade: "no século XXI, só há universidade quando há formação graduada e pós-graduada, pesquisa e extensão. Sem qualquer destes, há ensino superior, não há universidade" (SANTOS, 2017, p. 46-47 apud P12). Sobretudo, apesar de este ser um preceito que não se aplica às demais IES, como Centros de Educação Superior, Faculdades, Institutos Federais, há que se considerar que possa ser um conhecimento elaborado no contexto da formação profissional docente. Isto porque, conforme a vinculação institucional indicada pelos participantes da pesquisa, não há correspondência total entre participante professor universitário, sujeito que defende o princípio da indissociabilidade do ensinopesquisa-extensão, havendo professores de Institutos Federais e Faculdades com entendimentos ao encontro dela.

\section{Algumas considerações}

Apesar da ciência de que o processo de ATD das respostas de 69 professores da Educação Superior ao questionamento sobre a dimensão ensino, no referido nível de educação abordado neste estudo, não ter sido aqui esgotado, o conjunto das compreensões tecidas apresentadas nos leva a outras questões, talvez nem todas novas, como Moraes (2003) indica ser possível pela ATD, porém singulares. Os processos de unitarização e categorização permitiram desvelar novas compreensões, em perspectiva de "novo emergente", sendo que elas ocorrem nas tessituras entre saberes docentes, constituição profissional e as práticas 
institucionais, que podem potencializar a formação acadêmica e profissional ao encontro das exigências socioculturais, científicas e tecnológicas da contemporaneidade.

O novo emergente pode residir em compreensões singulares por meio das e nas tramas dos sujeitos da pesquisa. Cada um dos entendimentos constitui os sentidos desvelados no estudo. São ratificadas e corroboradas questões que circulam e condicionam práticas docentes. São evidenciadas dificuldades que mantêm desafios ou constituem novos. Nos encontros e desencontros das unidades que compuseram o corpus textual, a tessitura emergente é a complexidade de fatores envolvidos na indissociabilidade do ensino, da pesquisa e da extensão.

Algumas premissas se tornam condições para o estabelecimento e/ou manutenção dessa relação. Uma delas, talvez, possa ser a compreensão dos processos educativos como situados em um determinado espaço-tempo, desenvolvidos e vividos em um grupo social e em um período histórico, o que implica reconhecer os determinantes socioculturais e políticoadministrativos que os condicionam e constituem. No caso da Educação Superior, um contexto histórico que, situado em um Estado, se autodenomina democrático e republicano, é marcado por documentos normatizadores e legais, apesar de nem todos terem caráter de representação de anseios da comunidade acadêmica. Ao conhecer o passado e a implantação da Educação Superior, no Brasil, podemos compreender aspectos da atualidade, a qual, mesmo que muitas vezes ainda com oferta elitista, tencionou o ingresso de um número significativamente maior da população em cursos de bacharelado, tecnologia e de licenciatura, nas modalidades presencial e a distância. A partir dessa premissa, convém questionarmos: Por que se ampliou a oferta e sob quais condições? Acesso e qualidade equivalem-se na contemporaneidade da Educação Superior?

Compreender e situar a Educação Superior na contemporaneidade pode ser uma condição para buscar e lutar pela correlação acesso-qualidade. As IES, ao fomentarem o desenvolvimento científico, social e econômico brasileiro, de forma sustentável e contemporânea, cumprem função não só de capacitação profissional, mas de formação humana e acadêmica.

Ao professor e ao gestor do Ensino Superior importa, em especial, compreender que a oferta nesse nível de ensino exige compreendê-la como práxis que não se modela, define ou transforma por documentos legais, mas que muda ou se reorganiza conforme as demandas e as condições socioculturais e político-administrativas. Em perspectiva de contextualização, a indissociabilidade das atividades de ensino, pesquisa e extensão constituem-se meio e condição para a promoção de práticas institucionais e docentes articuladas social, cultural e cientificamente. Sem ser novo emergente, nos valemos da ideia de que desafios se interpõem. A questão é (re)conhecê-los e enfrentá-los.

\section{Referências}

ALARCÃO, I. Professores reflexivos em uma escola reflexiva. 8. ed. São Paulo: Cortez, 2011.

ALMEIDA, M. I. Formação do Professor do Ensino Superior: desafios e políticas institucionais. São Paulo: Cortez, 2012. (Coleção Docência em formação: Ensino Superior).

BRASIL. Conselho Nacional de Saúde. Resolução nº 510/2016, de 07 de abril de 2016. Brasília: Ministério da Saúde, 2016. 
CUNHA, M. I. Docência na Educação Superior: a professoralidade em construção.

Educação, 41, n. 1, p. 6-11, 2018. Disponível em: http://revistaseletronicas.pucrs.br/ojs/ index.php/faced/article/view/29725. Acesso em: 11 fev. 2020.

FRANCO, M. A. S. Didática: uma esperança para as dificuldades pedagógicas do Ensino Superior? Práxis Educacional, Vitória da Conquista, v. 9, n. 15, p. 147-166, jul./dez. 2013. Disponível em: https://pdfs.semanticscholar.org/ab9b/96a0b2bf90c21d19b7b1d188b7258 c85e252.pdf. Acesso em: 11 fev. 2020.

GAUTHIER, C. et al. Por uma teoria da pedagogia. 3. ed. Ijuí: Unijuí, 2013.

GOMES, V.; MACHADO-TAYLOR, M. L; SARAIVA, E. V. O Ensino Superior no Brasil: breve histórico e caracterização. Ciência \& Trópico. Recife, v. 42, n. 1, p. 106-129, 2018. Disponível em: https://fundaj.emnuvens.com.br/CIC/article/view/1647/1395. Acesso em: 11 fev. 2020.

LIBÂNEO, J. C. Conteúdos, formação de competências cognitivas e ensino com pesquisa: unindo ensino e modos de investigação. In: PIMENTA, S. G.; ALMEIDA, M. I. (org.).

Pedagogia universitária: caminhos para a formação de professores. São Paulo: Cortez, 2011.

LÜDKE, M.; ANDRÉ, M. E. D. A. Pesquisa em educação: abordagens qualitativas. São Paulo: EPU, 1986.

MORAES, R.; GALIAZZI, M. C. Análise textual discursiva: processo reconstrutivo de múltiplas faces. Ciência \& Educação, v. 12, n. 1, p. 117-128, 2006.

MORAES, R. Uma tempestade de luz: a compreensão possibilitada pela análise textual discursiva. Ciência \& Educação, v. 9, n. 2, p. 191-211, 2003.

NÓVOA, A. Os professores e as histórias da sua vida. In: NÓVOA, A. (org.). Vidas de professores. Porto: Porto Editora, 1992.

SAMPAIO, J. H.; FREITAS, M. H. A indissociabilidade entre Ensino, Pesquisa e Extensão. In: FREITAS, L. G.; FILHO, J. L. C.; MARIZ, R. S. Educação Superior: princípios, finalidades do ensino e formação continuada de professores. Brasília: Universa Liber Livro, 2010 .

SANTOS, B. S. A universidade no século XXI: para uma reforma democrática e emancipatória da universidade. 3.ed. São Paulo: Cortez, 2017.

SCHÖN, D. A. Formar professores como profissionais reflexivos. In: NÓVOA, A. (coord.). Os professores e a sua formação. Lisboa: Nova Enciclopédia, 1992.

Recebido em abril de 2020.

Aprovado em novembro de 2020. 